\title{
Pattern of mismatch repair protein loss and its clinicopathological correlation in colorectal cancer in North India
}

\author{
A Kumar, ${ }^{1}$ M Jain, ${ }^{1}$ R Saxena, ${ }^{1}$ A Yadav, ${ }^{1}$ N Kumari, ${ }^{2}$ N Krishnani ${ }^{2}$ \\ ${ }^{1}$ Departments of Surgical Gastroenterology and \\ ${ }^{2}$ Pathology, Sanjay Gandhi Postgraduate Institute of Medical Sciences, Lucknow-226014, India
}

Corresponding author: Prof. Ashok Kumar (doc.ashokgupta@gmail.com)

\begin{abstract}
Background: To determine the mismatch repair (MMR) protein loss in colorectal cancer (CRC) in north Indian patients and its clinicopathological correlation.

Methods: A prospective study on patients with colorectal cancer from a tertiary level hospital conducted between May 2014 and June 2015. MMR protein loss was determined using immunohistochemistry for MLH1, MSH2, PMS2 and MSH6.

Results: 52 patients (38 male and 14 females) of CRC, with median age of 52.5 years who underwent resection form the study group. $18(35 \%)$ patients were $<50$ years of age. Family history of malignancy was present in $3(6 \%)$ patients. A total of $15(29 \%)$ patients had loss of MMR protein of which $7(46 \%)$ were $<50$ years. Most common MMR loss was combined loss of MSH2 + MSH6 [6 (11.5\%)] followed by isolated loss of PMS2 [5 (9.6\%)]. MMR protein loss was more frequent in patients with right side colon cancer $[12(42 \%)]$ compared to left $[3(13 \%)](p=0.033)$. MMR protein loss was seen in 11 $(34 \%)$ out of 32 patients fulfilling the revised Bethesda criteria compared to $4(20 \%)$ out of 20 patients who did not fulfil the criteria $(\mathrm{p}=0.352)$.

Conclusion: This study demonstrates high frequency of MMR protein loss in colorectal cancer in north Indian patients which was more common in right colon cancer. Many patients having MMR protein loss do not satisfy the revised Bethesda criteria and would have been missed if selective testing was done. Further research and larger studies are required to validate these findings and develop India specific clinical criteria.

Key words: Colorectal Cancer, Hereditary nonpolyposis colon cancer (HNPCC), Immunohistochemistry, Lynch Syndrome, Microsatellite instability
\end{abstract}

S Afr J Surg 2018;56(1)

http://dx.doi.org/10.17159/2078-5151/2018/v56n1a2285

\section{Introduction}

Colorectal cancer (CRC) is the third most common malignancy in the USA with lifetime risk of about $4 \%$ and incidence of 40 per $100000 .^{1,2}$ Initially thought to be an uncommon cancer in India with incidence of 4 per 100000 but it is increasing over time. ${ }^{2,3}$ The cancer is not uncommon in young age. ${ }^{4}$ It can occur in sporadic form or may be hereditary. Sporadic form is the most common type but genetic and familial associations are known. Risk factors include increasing age, familial predisposition, obesity, smoking and red meat. ${ }^{5-7}$

Lynch syndrome is the most common genetic type. It is caused by mutations in the mismatch repair (MMR) genes, ${ }^{8}$ which is characterised by autosomal dominant inheritance, predominance for right side cancer and early age of onset. ${ }^{9}$ The diagnosis is clinched by genetic testing which is expensive and not readily available. Hence, before performing genetic testing, screening tests are performed to select patients most likely to benefit from genetic testing. This can be done by either testing for MMR protein expression using immunohistochemistry (IHC) or by microsatellite instability (MSI) testing using Bethesda markers. Clinical criteria (Amsterdam I and II) ${ }^{10,11}$ were initially suggested to make the clinical diagnosis of Lynch syndrome, but later revised Bethesda guidelines were used to select patients for subjecting to screening tests. ${ }^{12}$ But a large number of patients not satisfying the revised Bethesda criteria lack MMR protein expression or have microsatellite instability. ${ }^{13-15}$

There is hardly any data available from India on the given subject. In view of different cancer epidemiology between the west and India, the same cannot be extrapolated here. While cost constraints limit genetic testing to be performed, screening patients using IHC for MMR protein expression 
offers an economical alternative to select patients requiring genetic testing. ${ }^{16}$ Therefore, the present study has been carried out to find MMR protein loss in colorectal cancer in north India and whether there is any clinicopathological correlation.

\section{Methods}

A prospective study on patients with colorectal adenocarcinoma was conducted at Sanjay Gandhi Post Graduate Institute of Medical Sciences from May 2014 to June 2015. The study was approved by the Institute's ethics committee. All patients admitted with the diagnosis of colorectal cancer for surgery in the department of Surgical Gastroenterology formed the study group. Informed consent was taken from all patients. Patients known to have Familial Adenomatous Polyposis (FAP) and cancer arising in the background of inflammatory bowel disease (IBD) were excluded. After informed consent, detailed clinical history, imaging and histological findings were recorded on a defined proforma. IHC was performed as per described standard method.

\section{Immunohistochemistry}

Formalin fixed paraffin embedded CRC tissue blocks were sectioned with the help of microtome at $3 \mu \mathrm{m}$ thickness and collected on poly-lysine coated glass slides. Prior to immunostaining, sections were deparaffinised in xylene and rehydrated in an alcohol series $(100 \%, 70 \%$ and $30 \%$ then with water). Antigen retrieval was done in $1 \mathrm{X}$ EDTA (Ethylene diamine tetra acetic acid) buffer $\left(\mathrm{pH} \mathrm{9.0)}\right.$ at $90^{\circ} \mathrm{C}$ for 30 minutes in microwave. Slides were cooled at room temperature. Endogenous peroxidase activity was blocked by putting the slides in $3 \% \mathrm{H}_{2} \mathrm{O}_{2}$ in methanol for 25 minutes. Slides were incubated with the Anti-MMR antibodies (MLH1- SC56161, Santa Cruz biotechnology, 1:50 dilution, MSH2- SC56163, Santa Cruz biotechnology, 1:150 dilution, PMS2- SC617, Santa Cruz biotechnology, 1:50 dilution, MSH6- EP-49 Dako, Ready-to-use) at room temperature for 2 hours. Slides were washed with Tris-buffer saline (TBS) buffer ( 3 times). The slides were then incubated with the secondary antibody (Novolink, Maxpolymer detection system 1250, Leica Biosystems, Novacastra, Ready-to-use) for one hour at room temperature followed by washing with TBS three times. Slides were then incubated with 3,3'-Diaminobenzidine (DAB) for 10 minutes (DAB is a chromogenic substrate which stains antigen-antibody sites 'brown'). Counter staining was done by Haematoxylin and eosin. Complete absence of nuclear staining of tumour cells was regarded as loss of MMR protein expression.

\section{Statistical analysis}

Continuous data were reported as mean or median and discrete data were reported in percentage. Continuous nonnormally distributed variables were compared using 2 tailed student t- test and categorical variables were compared using chi-square test or Fisher's exact test using SPSS version 16.0 (IBM Corporation, Armonk, NY, USA). A $p$ value of $<0.05$ was considered as significant.

\section{Results}

During the study period, a total of 52 patients (38 male and 14 female) of colorectal cancer underwent resection. Median age of the patient was 52.5 (interquartile range 42-60) years. $18(35 \%)$ patients were younger than 50 years. Most common presenting symptom was abdominal pain $[\mathrm{n}=25(48 \%)]$. Family history of malignancy was present in $3(6 \%)$ patients of which two were in first degree relative and one in second degree relative.

Out of 52 patients, 38 (73\%) had colon cancer, while 14 (27\%) had rectal cancer. Also, 29 (57\%) patients had right sided lesion while 23 (43\%) had tumour distal to splenic flexure. Two patients had synchronous lesion, while 2 had metachronous lesion. Of these, one had both a synchronous and a metachronous lesion. Histopathological examination showed well differentiated tumour in $16(31 \%)$, moderately differentiated in $10(19 \%)$ and poorly differentiated lesion in $26(50 \%)$ patients. High risk histopathology (poorly differentiated, signet ring type, mucinous type, medullary type, Crohn's like reaction, tumour infiltration of lymphocytes) was present in $27(52 \%)$ patients. Revised Bethesda criteria were fulfilled by $32(61 \%)$ patients. Patient demographics, tumour location and histopathological characteristics are shown in Table 1.

MMR protein loss was found in $15(29 \%)$ patients. Of these, 7 were younger than 50 years. A positive family history was present in only 1 patient. Pattern of MMR loss is depicted in Table 2. Most common MMR protein loss was combined loss of MSH2 + MSH6 seen in $6(11.5 \%)$ followed by isolated loss of PMS2 in $5(9.6 \%)$ patients. Overall, loss of MLH1 was present in 1, loss of PMS2 in $6(11.5 \%)$, loss of MSH2 in 6 $(11.5 \%)$ and loss of MSH6 in $9(17.3 \%)$ patients.

There was no difference in MMR protein loss based on patient age, gender, tumour differentiation, tumour stage or tumour histopathological characteristics. MMR protein loss was seen more frequently in patients with right side colon cancer [12 (42\%)] as compared to left [3 (13\%)] which was statistically significant $(\mathrm{p}=0.033)$. There was no statistical difference in MMR protein loss even between early stage (Stage I/II) compared to late stage (III/IV) tumours. The difference was also not significant between low risk tumours (well/moderately differentiated and no high risk HPE features) compared to high risk tumours (poorly differentiated and high risk HPE features) (Table 3).

Out of 32 patients fulfilling the revised Bethesda criteria, MMR protein loss was seen in 11 (34.4\%) patients which was similar to patients not fulfilling the revised Bethesda criteria $(p=0.266)$.

\section{Discussion}

The present study represents one of the first few studies from north India to determine the loss of MMR protein expression in colorectal cancer. IHC was used because of its high sensitivity and specificity in detecting microsatellite instability. The sensitivity of IHC to detect MMR loss is $65-70 \%$ with the use of 2 antibodies (MLH1, MSH2) which 


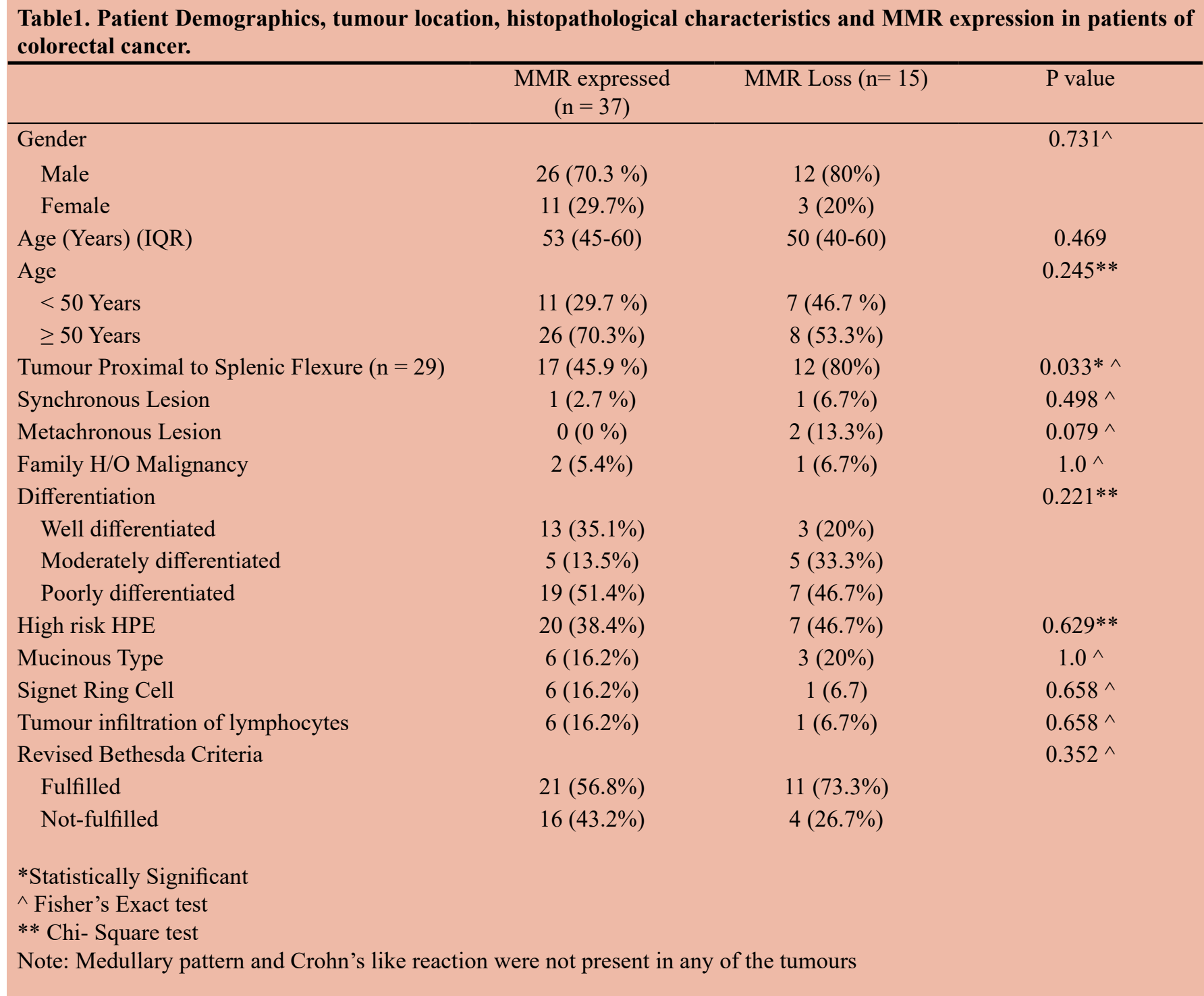

is further increased to $90-92 \%$ with use of all four antibodies (MLH1, MSH2, MSH6, PMS2).

The male to female distribution was $3: 1$ in this study compared to $1.2-1.5: 1$ in the west. ${ }^{17}$ It was $2.1: 1$ in a study reported from south India. ${ }^{18}$ In another study from south India comprising of right colon cancer only, male to female ratio was 2.4:1. ${ }^{19}$ In yet another study from Rajasthan (west India), the male to female ratio was $1.7: 1 .^{20}$ This shows an overall higher male to female ratio in India with large regional variations within India.

Thirty-five percent of our patients were under 50 years compared to only $10 \%$ in USA. ${ }^{17}$ A large regional variation in the age distribution is seen in India with cases less than 50 years representing $20-50 \%$ of the total cases. ${ }^{18-21}$ Colorectal cancer in India thus appears to be more frequent in younger patients compared to the west, with large regional variations. This may be because of different environmental factors or may represent a different genetic predisposition.

MMR protein loss of $29 \%$ in the present study is higher than previously reported. A study from the UK reported MMR protein loss of $21 \%$ while another from Memorial
Sloan-Kettering Cancer Centre reported it as 19\%; other studies from the west have reported MMR protein loss from $15-21 \% .^{22-24}$ Wenxue Zhi et al. from China reported MMR loss in $7 \%$ patients. ${ }^{25}$ A recent study from north India by Dubey et al. reported MSI- high in $22 \%$ patients. ${ }^{26}$ Earlier, two studies from India by Pandey et al..$^{27}$ and Malhotra et al. ${ }^{28}$ have reported MMR protein loss from $17.8-19.9 \%$. But both had reported their study with only 2 antibodies, i.e. MLH1 and MSH2 in contrast to the present study where all four antibodies were tested (MLH1, MSH2, MSH6, PMS2). MLH1 loss was reported in $15.7 \%$ patients by Pandey et al. and in $13.3 \%$ by Malhotra et al. compared to only $1.9 \%$ in this series. Such low rates of MLH1 loss could not be explained.

Lynch syndrome accounts for about 3-5\% of colorectal cancer which is caused by germline mutation in the MMR gene. Isolated loss of MLH1 is usually the result of promoter hypermethylation preventing its expression and hence is usually sporadic. The present study has no isolated MLH1 loss which may suggest a high proportion of Lynch syndrome amongst patients with MMR protein loss.

MMR protein loss is more commonly seen in right sided 
Table2. Pattern of MMR loss in patients with colorectal cancer.

\begin{tabular}{ll}
\hline MMR Protein Lost & No. of Patients $(\mathbf{n}=\mathbf{5 2})$ \\
\hline MSH2 + MSH6 & $6(11.5 \%)$ \\
PMS 2 Only & $5(9.6 \%)$ \\
MSH 6 only & $3(5.8 \%)$ \\
MLH1 + PMS2 & $1(1.9 \%)$
\end{tabular}

Table 3. MMR protein loss based on tumour stage and tumour characteristics.

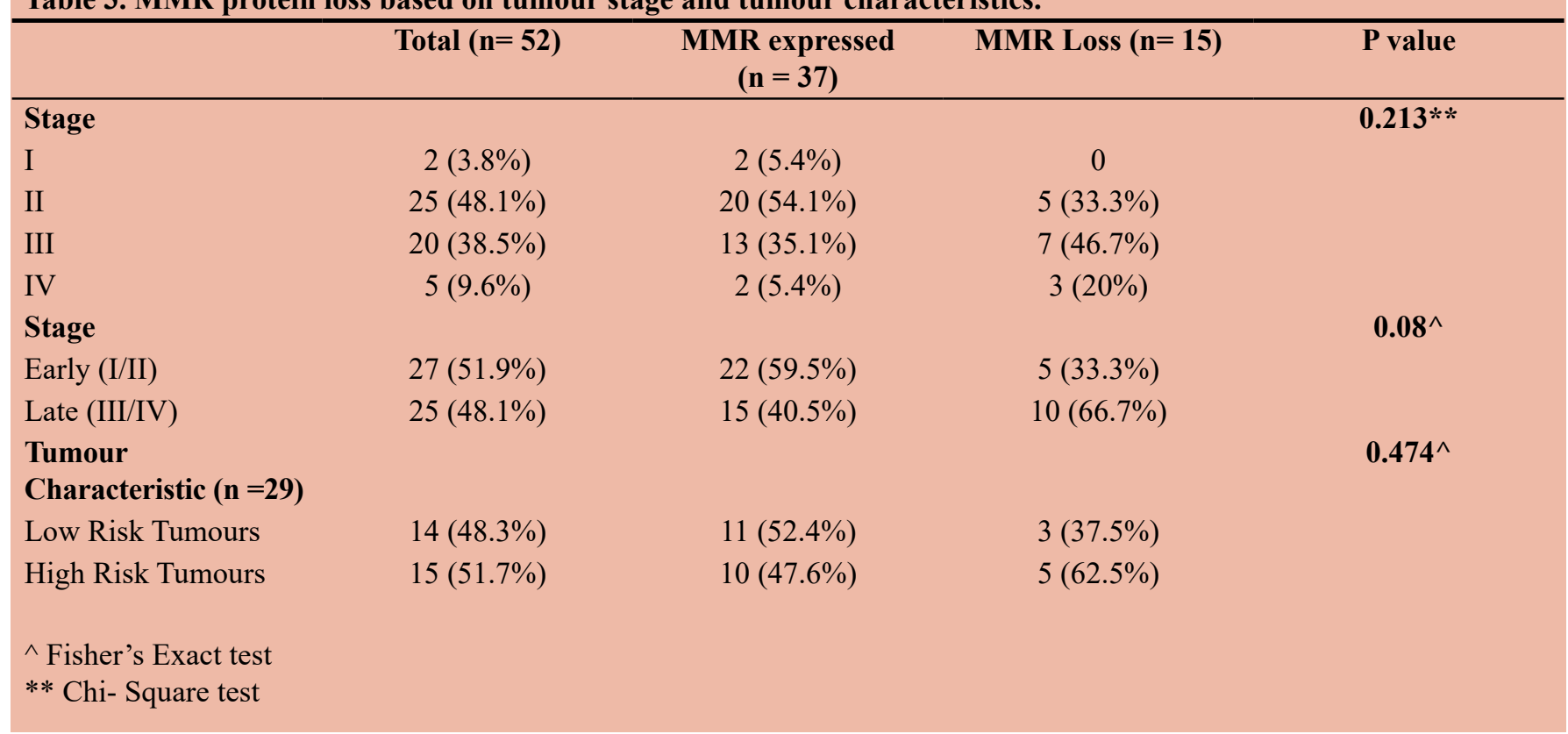

tumours compared to left sided and rectal tumours as was evident in this series as well. This is similar to studies from other parts of the world, ${ }^{24-26,29}$ however, Ravikanth et al. ${ }^{30}$ reported MSI-H status to be present most commonly in rectal cancer $(66 \%)$.

MMR protein testing using IHC is a less costly, rapid method compared to MSI testing, having similar sensitivity with the use of all 4 antibodies. It also directs further germline mutational analysis. ${ }^{22}$ Patients having MMR protein loss may be suspected to have Lynch syndrome, and warrant genetic testing. A major hurdle in this approach is lack of facilities for genetic counselling and testing. Even at places where such facility is available, IHC testing for MMR protein is not readily available. One of the factors for non-availability of a relatively economical IHC testing is lack of data regarding the prevalence of MMR protein loss in India; hence, its importance is not understood. A 29\% loss of MMR protein needs no further emphasis on the importance of MMR protein testing.

Out of 15 patients having MMR protein loss, 4 (27\%) patients did not meet the revised Bethesda criteria. Hence, onefourth MMR protein loss would have been missed if testing was done based on the above criteria alone. At the same time, $4(20 \%)$ patients out of 20 who did not satisfy the revised Bethesda criteria had MMR protein loss. Hence, if testing had been done solely based on revised Bethesda criteria, one-fifth of patients carrying the MMR protein loss would have been missed. Therefore, short of universal IHC testing, clinical criteria specific for Indian patients are required before genetic testing for patients of colorectal cancer.

The strength of the study lies in its prospective nature. However, the study lacks genetic analysis which is done to actually determine the patients suffering from Lynch syndrome. A correlation with MSI testing is also missing from the study.

\section{Conclusion}

This study demonstrates high frequency of MMR protein loss in colorectal cancer in north Indian patients which was more common in right colon cancer. Many patients with MMR protein loss do not satisfy the revised Bethesda criteria and would be missed if selective testing were done. Further research and larger studies are required to validate these findings and develop India specific clinical criteria.

Conflict of Interest: Authors declare that they have no conflict of interest to declare.

Funding: The study was funded by intra-mural grant by SGPGIMS, Lucknow.

Acknowledgement: The authors gratefully acknowledge Professors VK Kapoor, Anu Behari, Rajneesh Kumar Singh 
and Dr Anand Prakash for contributing case material for this study.

Note: Dr Ashok Kumar and Dr Mayank Jain have contributed equally in the study.

\section{REFERENCES}

1. Key statistics for colorectal cancer [Internet]. [cited 4 Sep 2016]. Available from: http://www.cancer.org/cancer/ colonandrectumcancer/detailedguide/colorectal-cancer-keystatistics

2. Ferlay J, Shin H-R, Bray F, Forman D, Mathers C, Parkin DM. Estimates of worldwide burden of cancer in 2008: GLOBOCAN 2008. Int J Cancer J Int Cancer. 15 Dec 2010;127(12):2893-917. PMID: 21351269

3. Yeole BB. Trends in cancer incidence in esophagus, stomach, colon, rectum and liver in males in India. Asian Pac J Cancer Prev APJCP. Mar 2008;9(1):97-100. PMID: 18439085.

4. Gupta S, Bhattacharya D, Acharya AN, Majumdar S, Ranjan P, Das S. Colorectal carcinoma in young adults: a retrospective study on Indian patients: 2000-2008. Colorectal Dis Off J Assoc Coloproctology G B Irel. Oct 2010;12(10 Online):e182-189. PMID: 20128837.

5. Norat T, Bingham S, Ferrari P, Slimani N, Jenab M, Mazuir $\mathrm{M}$, et al. Meat, fish, and colorectal cancer risk: the European Prospective Investigation into cancer and nutrition. J Natl Cancer Inst. 15 Jun 2005;97(12):906-16. PMID: 15956652.

6. Ji B-T, Dai Q, Gao Y-T, Hsing AW, McLaughlin JK, Fraumeni $\mathrm{JF}$, et al. Cigarette and alcohol consumption and the risk of colorectal cancer in Shanghai, China. Eur J Cancer Prev Off J Eur Cancer Prev Organ ECP. Jun 2002;11(3):237-44. PMID: 12131657.

7. Harriss DJ, Atkinson G, Batterham A, George K, Cable NT, Reilly T, et al. Lifestyle factors and colorectal cancer risk (2) a systematic review and meta-analysis of associations with leisure-time physical activity. Colorectal Dis Off J Assoc Coloproctology G B Irel. Sep 2009;11(7):689-701. PMID: 19207713.

8. Peltomäki P, Vasen HF. Mutations predisposing to hereditary nonpolyposis colorectal cancer: database and results of a collaborative study. The International Collaborative Group on Hereditary Nonpolyposis Colorectal Cancer. Gastroenterology. Oct 1997;113(4):1146-58. PMID: 9322509.

9. Lynch HT, Watson P, Lanspa SJ, Marcus J, Smyrk T, Fitzgibbons RJ, et al. Natural history of colorectal cancer in hereditary nonpolyposis colorectal cancer (Lynch syndromes I and II). Dis Colon Rectum. Jun 1988;31(6):439-44. PMID: 3378468.

10. Vasen HF, Mecklin JP, Khan PM, Lynch HT. The International Collaborative Group on Hereditary Non-Polyposis Colorectal Cancer (ICG-HNPCC). Dis Colon Rectum. May 1991;34(5):424-5. PMID: 2022152.

11. Vasen HF, Watson P, Mecklin JP, Lynch HT. New clinical criteria for hereditary nonpolyposis colorectal cancer (HNPCC, Lynch syndrome) proposed by the International Collaborative group on HNPCC. Gastroenterology. Jun 1999;116(6):1453-6. PMID: 10348829.

12. Umar A, Boland CR, Terdiman JP, Syngal S, de la Chapelle A, Rüschoff J, et al. Revised Bethesda Guidelines for hereditary nonpolyposis colorectal cancer (Lynch syndrome) and microsatellite instability. J Natl Cancer Inst. 18 Feb 2004;96(4):261-8. PMID: 14970275.

13. Julié $\mathrm{C}$, Trésallet $\mathrm{C}$, Brouquet $\mathrm{A}$, Vallot $\mathrm{C}$, Zimmermann $\mathrm{U}$, Mitry E, et al. Identification in daily practice of patients with Lynch syndrome (hereditary nonpolyposis colorectal cancer): revised Bethesda guidelines-based approach versus molecular screening. Am J Gastroenterol. Nov 2008;103(11):2825-35; quiz 2836. PMID: 18759827

14. Morrison J, Bronner M, Leach BH, Downs-Kelly E, Goldblum JR, Liu X. Lynch syndrome screening in newly diagnosed colorectal cancer in general pathology practice: from the revised Bethesda guidelines to a universal approach. Scand J Gastroenterol. Nov 2011;46(11):1340-8. PMID: 21879804.

15. Pérez-Carbonell L, Ruiz-Ponte C, Guarinos C, Alenda C, Payá A, Brea A, et al. Comparison between universal molecular screening for Lynch syndrome and revised Bethesda guidelines in a large population-based cohort of patients with colorectal cancer. Gut. Jun 2012;61(6):865-72. PMID: 21868491.

16. Mvundura M, Grosse SD, Hampel H, Palomaki GE. The costeffectiveness of genetic testing strategies for Lynch syndrome among newly diagnosed patients with colorectal cancer. Genet Med. 2010;12(2):93-104. PMID: 20084010.

17. Siegel R, DeSantis C, Jemal A. Colorectal cancer statistics, 2014. CA Cancer J Clin. 1 Mar 2014;64(2):104-17. PMID: 24639052.

18. Peedikayil MC, Nair P, Seena SM, Radhakrishnan L, Sadasivan S, Naryanan VA, et al. Colorectal cancer distribution in 220 Indian patients undergoing colonoscopy. Indian J Gastroenterol. 2009;28(6):212-5.

19. Franklyn J, Mittal R, Sebastian T, Perakath B. Demographics and outcomes of surgically treated right sided colon cancer in India: a 9-year single institution experience. Trop Gastroenterol. 13 Apr 2017;37(1):46-52.

20. Kumari P, Sharma N, Khatri PK, Narayan S, Kumari S, Harsh $\mathrm{KK}$, et al. Age wise distribution of colorectal cancer: An institutional observational study. IOSR J Dent Med Sci. Jan 2017;16(01):01-5.

21. Cherian T, Mahadevan P, Chandramathi S, Govindan J, Mathew IL. Increasing cancer incidence in a tertiary care hospital in a developing country, India. Indian J Cancer. 1 Jan 2015;52(1):133.

22. Colling R, Church DN, Carmichael J, Murphy L, East J, Risby P, et al. Screening for Lynch syndrome and referral to clinical genetics by selective mismatch repair protein immunohistochemistry testing: an audit and cost analysis. J Clin Pathol. Dec 2015;68(12):1036-9. PMID: 26201544.

23. Lee-Kong SA, Markowitz AJ, Glogowski E, Papadopoulos C, Stadler Z, Weiser MR, et al. Prospective immunohistochemical analysis of primary colorectal cancers for loss of mismatch repair protein expression. Clin Colorectal Cancer. Oct 2010;9(4):255-9. PMID: 20920999.

24. Zumstein V, Vinzens F, Zettl A, Heinimann K, Koeberle D, von Flüe M, et al. Systematic immunohistochemical screening for Lynch syndrome in colorectal cancer: a single centre experience of 486 patients. Swiss Med Wkly. 2016;146:w14315. PMID: 27152634.

25. Zhi W, Ying J, Zhang Y, Li W, Zhao H, Lu N, et al. DNA Mismatch Repair Deficiency in Colorectal Adenocarcinoma and its Association with Clinicopathological Features. J Clin Exp Pathol. 2015;5:220. doi:10.4172/2161-0681.1000220

26. Dubey AP, Vishwanath S, Nikhil P, Rathore A, Pathak A. Microsatellite instability in stage II colorectal cancer: An Indian perspective. Indian J Cancer. 1 Oct 2016;53(4):513.

27. Pandey V, Prabhu JS, Payal K, Rajan V, Deepak C, Barde S, et al. Assessment of microsatellite instability in colorectal carcinoma at an Indian center. Int J Colorectal Dis. Jul 2007;22(7):777-82. PMID: 17160686.

28. Malhotra P, Anwar M, Kochhar R, Ahmad S, Vaiphei K, Mahmood S. Promoter methylation and immunohistochemical expression of hMLH1 and hMSH2 in sporadic colorectal cancer: a study from India. Tumour Biol J Int Soc Oncodevelopmental Biol Med. Apr 2014;35(4):3679-87. PMID: 24317816.

29. Cheah P-L, Looi L-M, Teoh K-H, Rahman NA, Wong L-X, Tan S-Y. Colorectal carcinoma in Malaysians: DNA mismatch repair pattern in a multiethnic population. Asian Pac J Cancer Prev APJCP. 2014;15(7):3287-91. PMID: 24815484.

30. Kanth VVR, Bhalsing S, Sasikala M, Rao GV, Pradeep R, Avanthi US, et al. Microsatellite instability and promoter hypermethylation in colorectal cancer in India. Tumour Biol J Int Soc Oncodevelopmental Biol Med. May 2014;35(5):434755. PMID: 24408015 